\title{
FERRAMENTAS UTILIZADAS NA GESTÃO DA QUALIDADE
}

\section{ARTIGO DE REVISÃO}

PEREIRA, Paulo Eduardo Galdino ${ }^{1}$

\section{PEREIRA, Paulo Eduardo Galdino. Ferramentas utilizadas na gestão da qualidade.} Revista Científica Multidisciplinar Núcleo do Conhecimento. Ano 05, Ed. 11, Vol. 14, pp. 05-19. Novembro de 2020. ISSN: 2448-0959, Link de acesso: https://www.nucleodoconhecimento.com.br/engenharia-deproducao/ferramentas-utilizadas

\section{RESUMO}

O presente artigo apresenta um estudo das ferramentas da qualidade, tendo como objetivo discutir algumas destas ferramentas, e a importância da utilização na engenharia; foi utilizada no artigo a metodologia de pesquisas bibliográficas dos principais autores da área de engenharia, sendo a pesquisa do tipo qualitativa. Além da pesquisa contribuir para ampliar o conhecimento dos engenheiros, sendo exposto assuntos da qualidade e a sua gestão nas empresas; pois os negócios formados por pequenas e grandes empresas na produção de produtos e serviços nos últimos anos, vem ocorrendo mudanças nos processos para medir e aumentar a qualidade dos produtos ofertados aos clientes finais. E as empresas dando a devida importância do seu uso no ambiente de produção, vários autores aborda a utilização da qualidade, em que as organizações precisão ficar atualizadas nesse novo panorama no mercado internacional.

${ }^{1}$ Especialista em engenharia de produção-UBC, MBA em gestão empresarial UNICSUL, Graduação em análise e desenvolvimento de sistemas - UMC, Licenciatura em Matemática - UNICSUL, Ensino Técnico em Técnico em informática - ETEC -Centro Paula Souza. 
Palavras-chave: Qualidade, ferramenta, gestão, organização.

\section{INTRODUÇÃO}

Nos últimos anos as organizações vêm sofrendo uma grande transformação pelo crescimento dos diversos setores da economia, através da globalização dos produtos ofertados no mercado internacional. Necessitando das companhias uma nova abordagem no processo de gestão da qualidade das suas operações, tanto por influência externa ou interna.

Com esse cenário atual as empresas precisam modificar alguns dos seus processos de prestação de serviço e de oferta de produto, assegurando que os produtos estejam em uma margem de qualidade aceitável para o cliente final.

Silva (2008, p.303) afirma que "Os sistemas de informações são essenciais no processo de controle, porque proveem a base para a documentação, o armazenamento, e a distribuição dos resultados de desempenho".

A tecnologia avançou muitos na última década com empresas investindo muito em tecnologia da informação, para o sucesso dos seus negócios, utilizando sistemas informatizados para fazer os gerenciamentos de processos existentes na organização; os processos antes feitos manualmente, sendo gradativamente automatizados, ganhando em produtividade. Com esses fatores teve um aumento da concorrência internacionalmente, precisando as empresas a implementar ou reformular novos processos para a gestão da qualidade, suficiente para melhorar os produtos ofertados.

Seleme (2012, p.18) afirma que "As organizações, ao longo de usa existência, criaram métodos e ferramentas para garantir sua manutenção no mercado. Entretanto, isso somente ocorreu em função das exigências das pessoas que compunham o mercado". 
Através da implementação de métodos de controle de qualidade os processos poderão ser melhorados, para refletir nos resultados final e reduzir os custos e perdas de horas de trabalho.

O objetivo do trabalho e apresentar as ferramentas da qualidade, e a importância da utilização na engenharia. Além de contribuir para ampliar o conhecimento dos engenheiros, de algumas ferramentas existentes que podem ser utilizados.

O artigo está estruturado em apresentação do referencial teórico, descrevendo os principais conceitos ao tema proposto, metodologia, resultados e discussões e consideração finais.

\section{METODOLOGIA}

Fonseca (2002) citado por Gerhardt e Silveira (2009, p. 37)," A pesquisa bibliográfica é feita a partir do levantamento de referências teóricas já analisadas, e publicadas por meios escritos e eletrônicos, como livros, artigos científicos, páginas de web sites."

Diante do tema a ser pesquisado e o objetivo pretendido, o procedimento adotado no estudo e a pesquisa bibliográfica, se trata de levantamento teórico sobre o assunto, de autores da área administrativa e engenharia, sem ter a particularidade de aplicação prática.

Segundo Gerhardt e Silveira (2009, p. 31), "A pesquisa qualitativa não se preocupa com representatividade numérica, mas, sim, com o aprofundamento da compreensão de um grupo social, de uma organização, etc."

O tipo de pesquisa será a qualitativa, requerendo a análise teórica no processo da pesquisa, não precisando de técnicas estáticas. 


\section{RESULTADOS E DISCUSSÃO}

\subsection{ORGANIZAÇÃO}

De acordo com Chiavenato (2003), toda organização precisa funcionar como um sistema integrado e coeso, em que todas as suas partes se inter-relacionam intimamente, para atuar como uma totalidade a fim de alcançar um objetivo com sucesso.

Segundo Stair e Reynolds (2011), uma organização é um sistema de trabalho com mecanismo de realimentação, processamento e saída, utilizando combinação de esforços individuais para a realizar propósitos da empresa.

Toda organização precisa estar atualizada, estar munido de ferramentas adequadas para que consiga comandar suas operações de forma eficiente visando atingir seus ideais.

Segundo Maximiano (2007, p.4), "uma organização é um sistema de trabalho, que transforma recursos em produtos e serviços".

Por meio de uma organização torna-se possível, perseguir e alcançar objetivos que seriam inatingíveis por uma pessoa. (MAXIMIANO, 2009).

Cada organização tem a sua estrutura em função dos objetivos pretendidos, produtos que fabrica ou dos serviços que realiza; com fato, não tem duas organizações idênticas e dentro do modelo tradicional existe a linear, funcional e linha-staff cada qual com a sua racionalidade. (CHIAVENATO, 2003).

Segundo Maximiano (2007, p.4), as organizações estão por toda parte como "A ONU, a prefeitura, a padaria da esquina, o aeroporto internacional, também".

Segundo Silva (2008), a informação e a base do controle administrativo, qualquer sistema de controle da a informação correta tendo como objetivo a realização da tarefa e a difusão dos resultados na organização. 


\subsection{QUALIDADE}

O conceito de qualidade tem a sua origem na relação das organizações com o mercado nacional e internacional, referente ao padrão da produção e serviços fornecidos aos seus clientes. Mesmo o conceito ser difundido mundialmente, ainda as suas ferramentas não são completamente conhecidas em algumas empresas de pequeno porte, ocorrendo que produtos com boas ideias, não sejam comercializados por causa da qualidade abaixo do esperado. (SELEME, 2012).

Segundo Mello (2011, p.2), a qualidade está diretamente ligada a três fatores, redução de custos, aumento de produtividade e satisfação dos clientes. Partindo desse princípio fazer melhor, com menor custo, entregando ao consumidor produtos que corresponda a suas expectativas ou que as superam.

Figura 1 - Conceito Básico de Qualidade

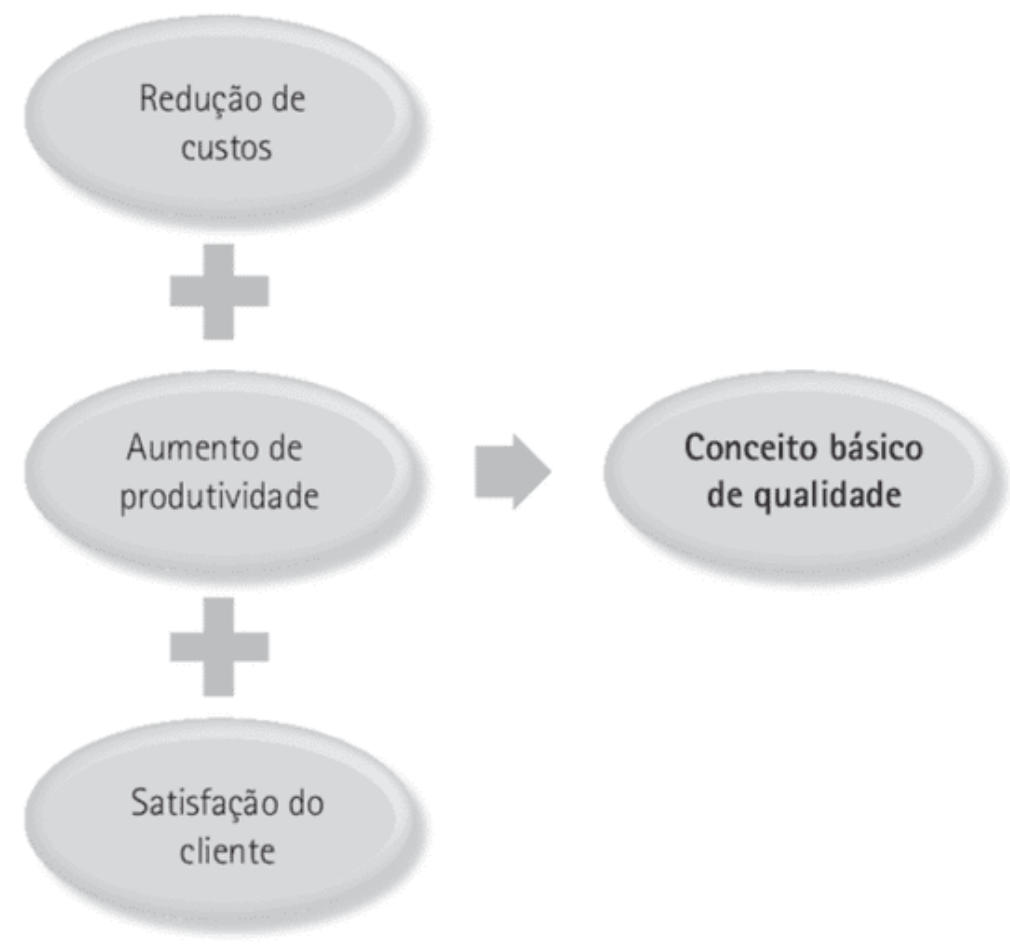

Fonte: Gestão da qualidade, Mello (2011) - ADAPTAÇÃO 
A qualidade não e usada somente pela empresa que fabrica ou oferece serviços sem ter erros e prestam excelentes serviços, mas também e utiliza por clientes que se recusam a adquirir os produtos a preço justo com o mínimo de qualidade possível. Os consumidores querem produtos inovadores com o menor prazo possível com uma qualidade aceitável no sentido de durabilidade, mesmo que isso seja um desafio para as empresas atualmente. (SILVA, 2008, p.25).

Segundo Seleme (2012, p.11), "A qualidade não e apenas mais uma opção das instituições, poias a concorrência utiliza metodologias e ferramentas com objetivos de extrais delas todo o potencial de melhoria e aceitação dos produtos."

Qualidade não gera custos pelo contrário ela os diminui, por reduzir a quantidade de erros nos processos possibilita a redução do tempo de fabricação, evitar desperdício de recursos e mais satisfação do trabalhador. Assim ao fazer o planejamento correto da qualidade antes de um produto ou serviço for oferecido evita perca de dinheiro e retrabalho dos profissionais. (MELLO, 2011).

\subsection{GESTÃO DA QUALIDADE}

A qualidade teve ser considerada como fator estratégico para atender o consumidor, cabendo os líderes da empresa promover a gestão da qualidade, mostrando que cada pessoa tem um papel importante, dentro da cadeia produtiva e a figura do chefe não e mais aceitável em um modelo que todos participam. Podendo os chefes estabelecer uma rotina de gerenciamento da qualidade, lideradas pelo gerente em grupos multifuncionais de vários departamentos dentro da empresa, com o objetivo reportar os problemas de conformidade e distribuir novas atividades para os responsáveis. (SILVA, 2008, p.61). 
Figura 2 - Estrutura da reunião com grupos multifuncionais focada na qualidade

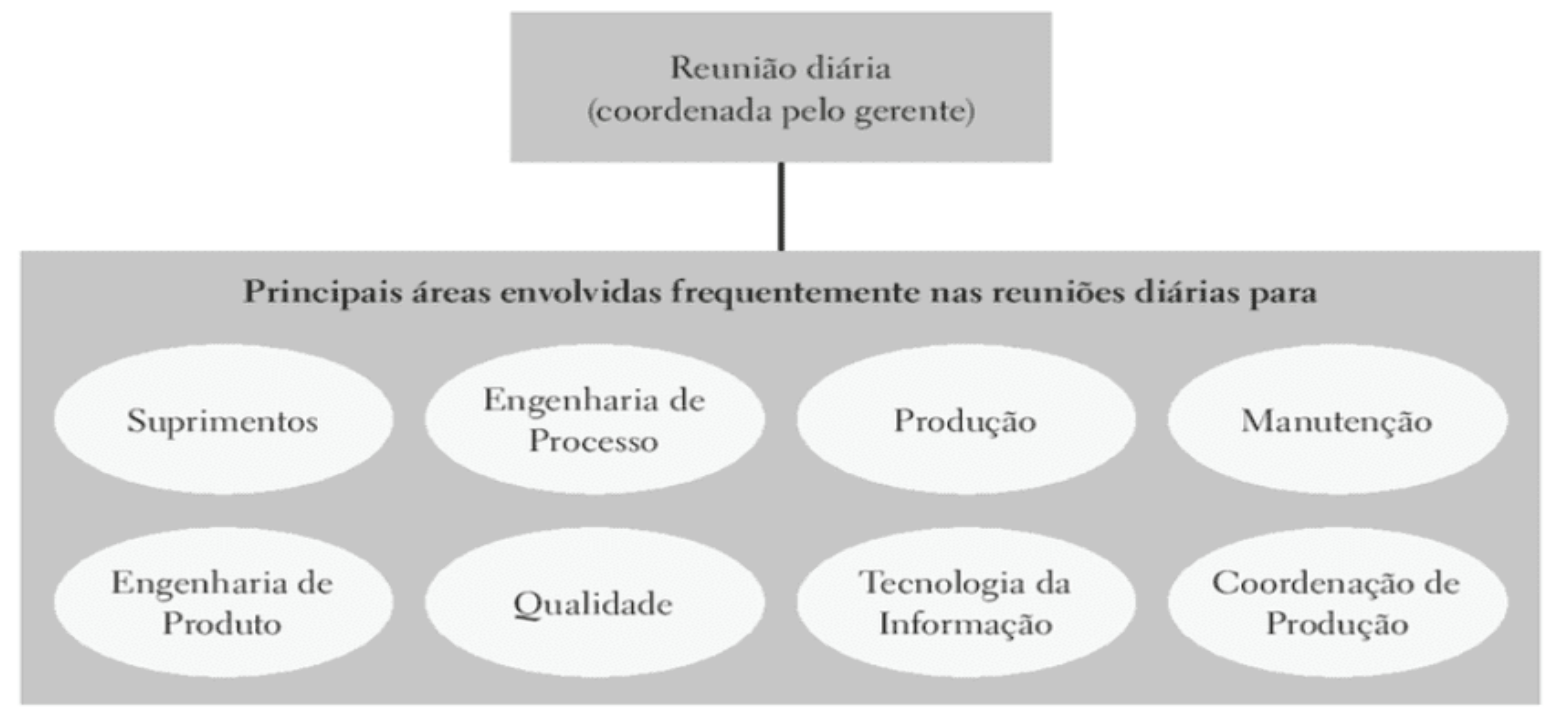

Fonte: Gestão da qualidade, Silva (2017) - ADAPTAÇÃO

"Na década de 1970, o ocidente começou a reagir a hegemonia dos produtos japoneses no tocante a qualidade. Iniciou se, então, o período que ficaria conhecido como era da gestão da qualidade total, cuja principal característica e o foco no cliente e nos processos de gestão". (MELLO, 2011, p.12).

Figura 3 - Evolução da qualidade no âmbito organizacional

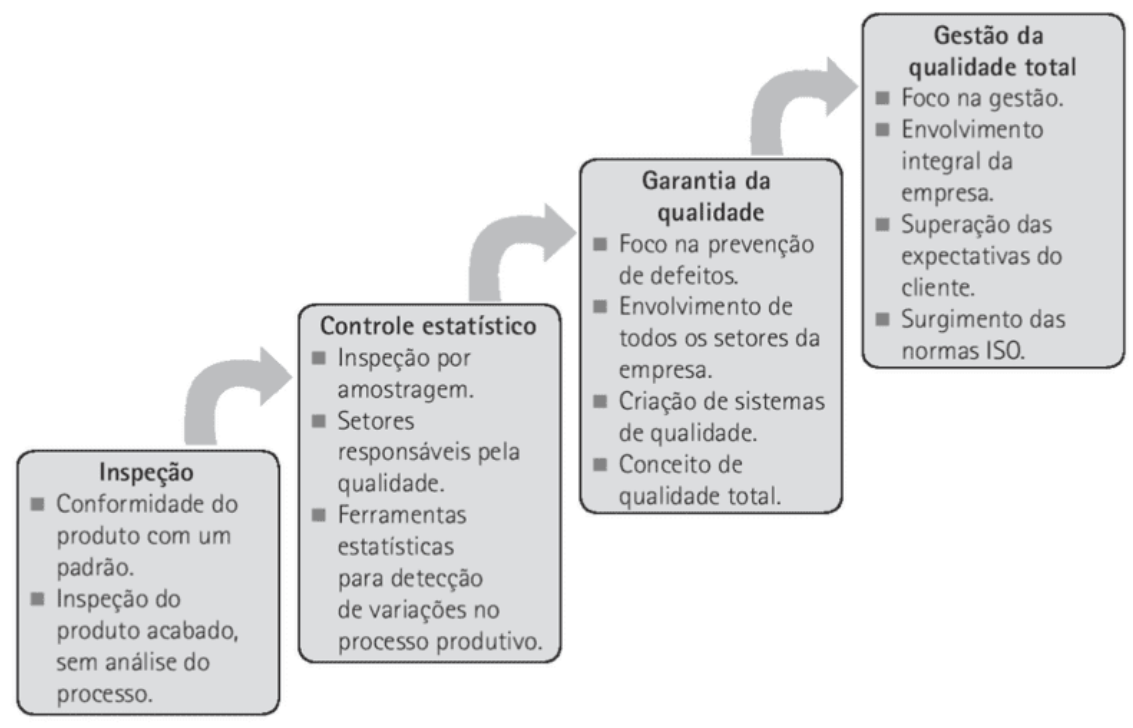

Fonte: Gestão da qualidade, Mello (2011) - ADAPTAÇÃO

RC: 65285

Disponível em: https://www.nucleodoconhecimento.com.br/engenharia-de-producao/ferramentasutilizadas 


\subsection{SISTEMA DE GESTÃO DA QUALIDADE}

Para Germano (2013), o sistema e o conjunto de elementos que auxilia a orientação da empresa por garantir a confiabilidade nos fornecimentos dos produtos, aos mercados alvos que não aceitam que as empresas descontam erros ou vícios ocultos.

Para Custodio (2015), os requisitos gerais do sistema precisam identificar os processos, determinar a sequência e a interação entre os processos, assegurar a eficácia e o controle da operação, assegurar a disponibilidade de recursos e informações, monitorar, medir e analisar os processos e implementar a coes para o alcance dos resultados esperados e para melhoria continua.

\subsection{FERRAMENTAS DA QUALIDADE}

Segundo Barros (2014), a evolução mundial e a competitividade exigem das organizações um investimento na qualidade dos produtos, com clientes mais exigentes necessita que os processos de fabricação ou prestação de serviços estevam livres de problemas erros, possibilitando a oferta com preço justo; Os erros nos processos necessita de uma intervenção em vários setores para serem corrigidos com eficácia, não podendo ser alcançado em uma abordagem individual.

Para Mello (2011), as ferramentas da qualidade vêm para auxiliar a empresa e a equipe, através dos dados levantados para serem compreendidos e utilizado para resolver possíveis causas de erro na produção. Mas é preciso saber quando usá-las corretamente os tipos de ferramentas e métodos existem atualmente, para alcançar a qualidade desejada.

De acordo com Barros (2014), existe 7 ferramentas básicas para o controle da qualidade:

- Diagrama de Causa e Efeito;

- Folha de verificação;

- Histograma; 
- Gráfico de Pareto;

- Diagrama de dispersão/correlação;

- Fluxograma;

- Gráfico de controle.

Diagrama de Causa e Efeito: O diagrama e utilizado para mostrar a relação entre a causa e efeito de um processo, quando o processo não tiver o efeito esperado e necessário ver as causas analisando a medição, materiais mão de obra, máquinas, métodos e meio ambiente. (MELLO, 2011).

Figura 4 - Exemplo de aplicação do Diagrama de Causa e Efeito

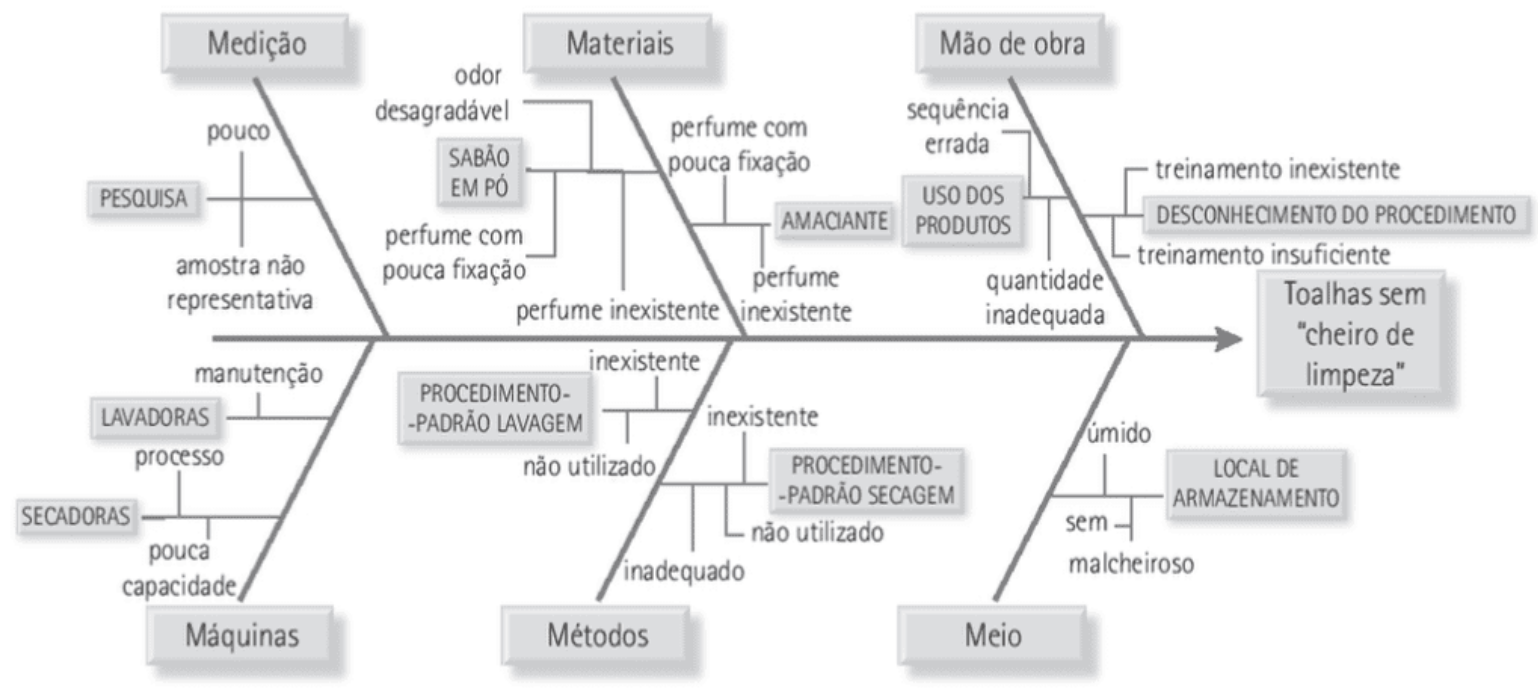

Fonte: Gestão da qualidade, Mello (2011) - ADAPTAÇÃO

Folha de verificação: e um ponto de partida para o controle da qualidade, essa folha necessita ter título, período de observação e evento. Com ela e possível análise de processos e a melhoria da qualidade através da identificação dos defeitos e variação para serem realizados ações efetivas focada no problema. (BARROS, 2014).

Disponível em: https://www.nucleodoconhecimento.com.br/engenharia-de-producao/ferramentasutilizadas 
Figura 5 - Exemplo de Folha de verificação de um processo

\begin{tabular}{|c|c|c|}
\hline \multicolumn{3}{|c|}{$\begin{array}{l}\text { Processo analisado: produção de bolos } \\
\text { Quantidade produzida/dia: } 2.000 \text { unidades } \\
\text { Amostra verificada: } 10 \% \text { (20 unidades) } \\
\text { Data da verificação: 18/06/2010 } \\
\text { Frequência da verificação: diária }\end{array}$} \\
\hline Defeito & Frequência & Soma \\
\hline Massa pesada & IIIIII & 6 \\
\hline Recheio pouco cremoso & II & 2 \\
\hline Pouca cobertura & IIII & 4 \\
\hline Sabor excessivamente doce & 1 & 1 \\
\hline Sabor artificial & 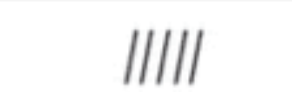 & 5 \\
\hline
\end{tabular}

Fonte: Gestão da qualidade, Mello (2011) - ADAPTAÇÃO

Histograma: e um diagrama de barras que deve atender 3 requisitos, as barras precisar ser desenhadas encostas entre elas, no eixo vertical dever ficar a frequência da classe e o eixo horizontal as subdivisões. (BONAFINI, 2015).

"Por meio do histograma e possível conhecer a distribuição dos dados coletados em uma linha temporal, bem como sua variação em uma amostra". (MELLO, 2011).

Para Barros (2014), e uma ferramenta que facilita a análise de uma grande quantidade de dados, para um entendimento maior do problema. 
Figura 6 - Exemplo de Histograma

\section{Exemplo de histograma.}

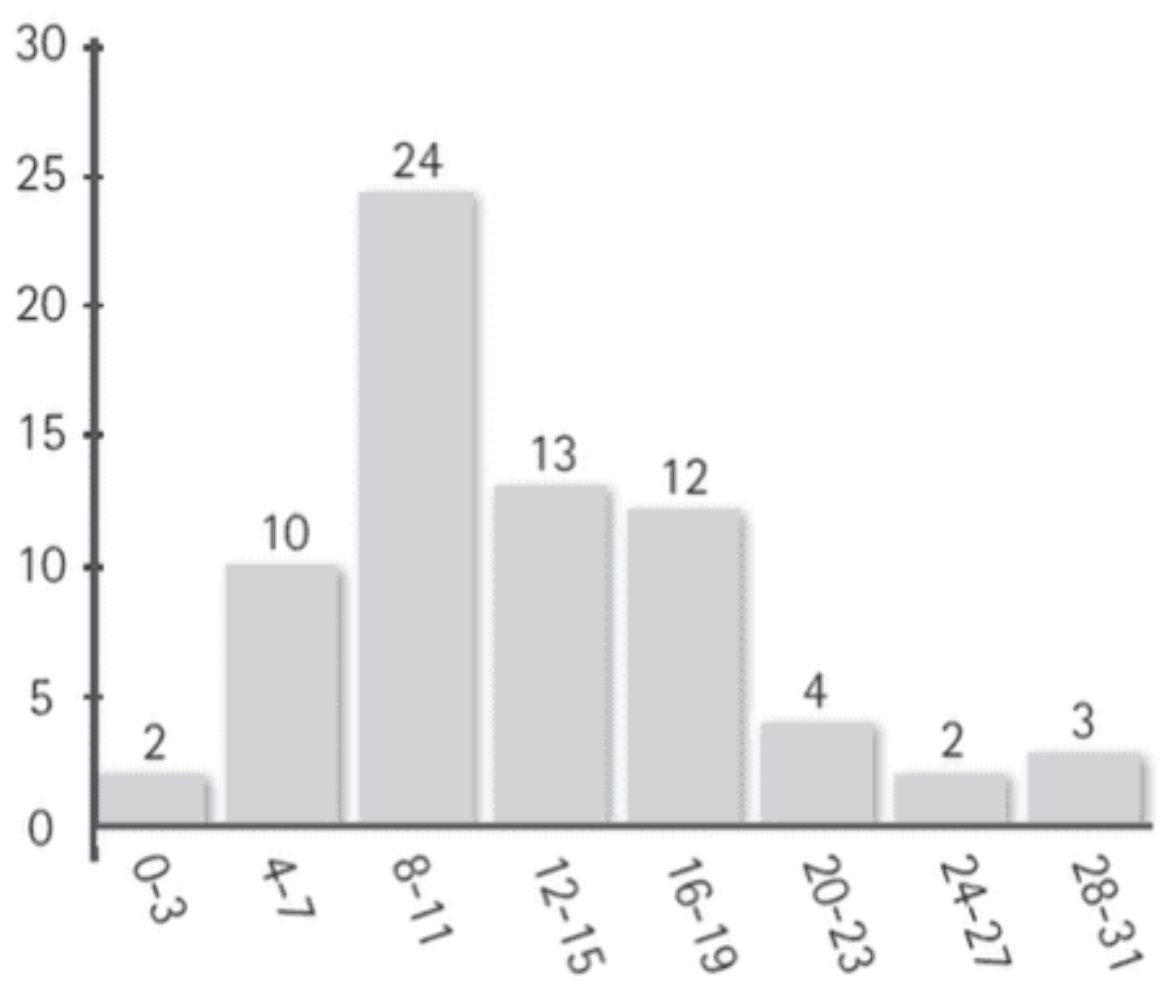

Fonte: Gestão da qualidade, Mello (2011) - ADAPTAÇÃO

Gráfico de Pareto: "foi proposto por Juran, com base no princípio de Pareto, segundo o qual $80 \%$ dos efeitos derivam de $20 \%$ das causas. Esse princípio e conhecido também como 80/20." (MELLO, 2011).

Para Barros (2014), no termo de qualidade e mais favorável um foco na melhoria dos procedimentos do que tentar alterar todo o processo. Para a sua construção os dados devem ser organizados como essenciais e secundários os fatores e as causas. 
Figura 7 - Exemplo de Gráfico de Pareto

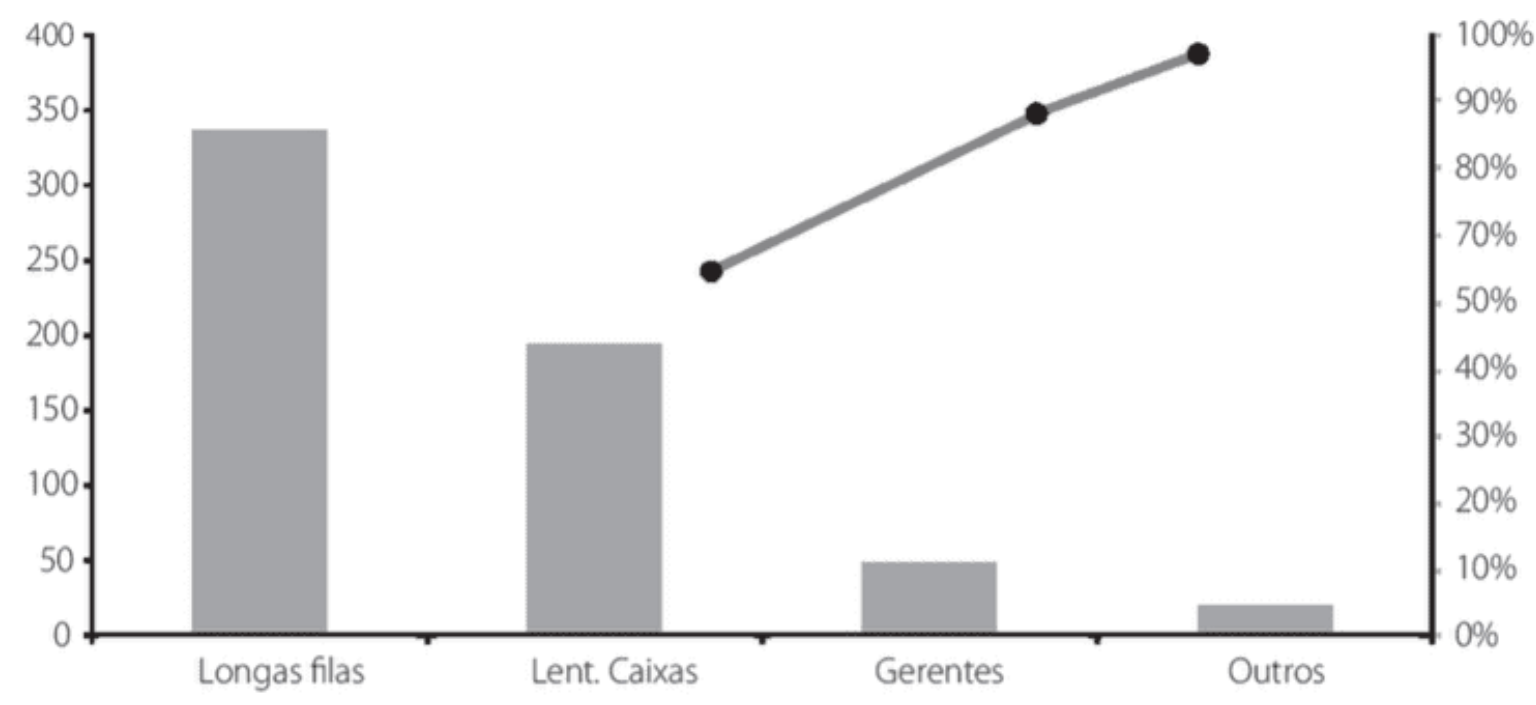

Fonte: Ferramentas da Qualidade, Barros (2014) - ADAPTAÇÃO

Diagrama de dispersão/correlação: e um diagrama que pode mostrar a relação de 2 variáveis ou mais, a concentração são os pontos no gráfico que serve para analisar a relação dos pontos que permite traçar o perfil do comportamento da relação. (MELLO, 2011).

"como todo gráfico, ele deve ser autoexplicativo. Assim, são desenvolvidos para serem utilizados, e, portanto, devem ser analisados". (BARROS, 2014, p. 54). 
Figura 8 - Exemplo de Diagrama de dispersão/correlação

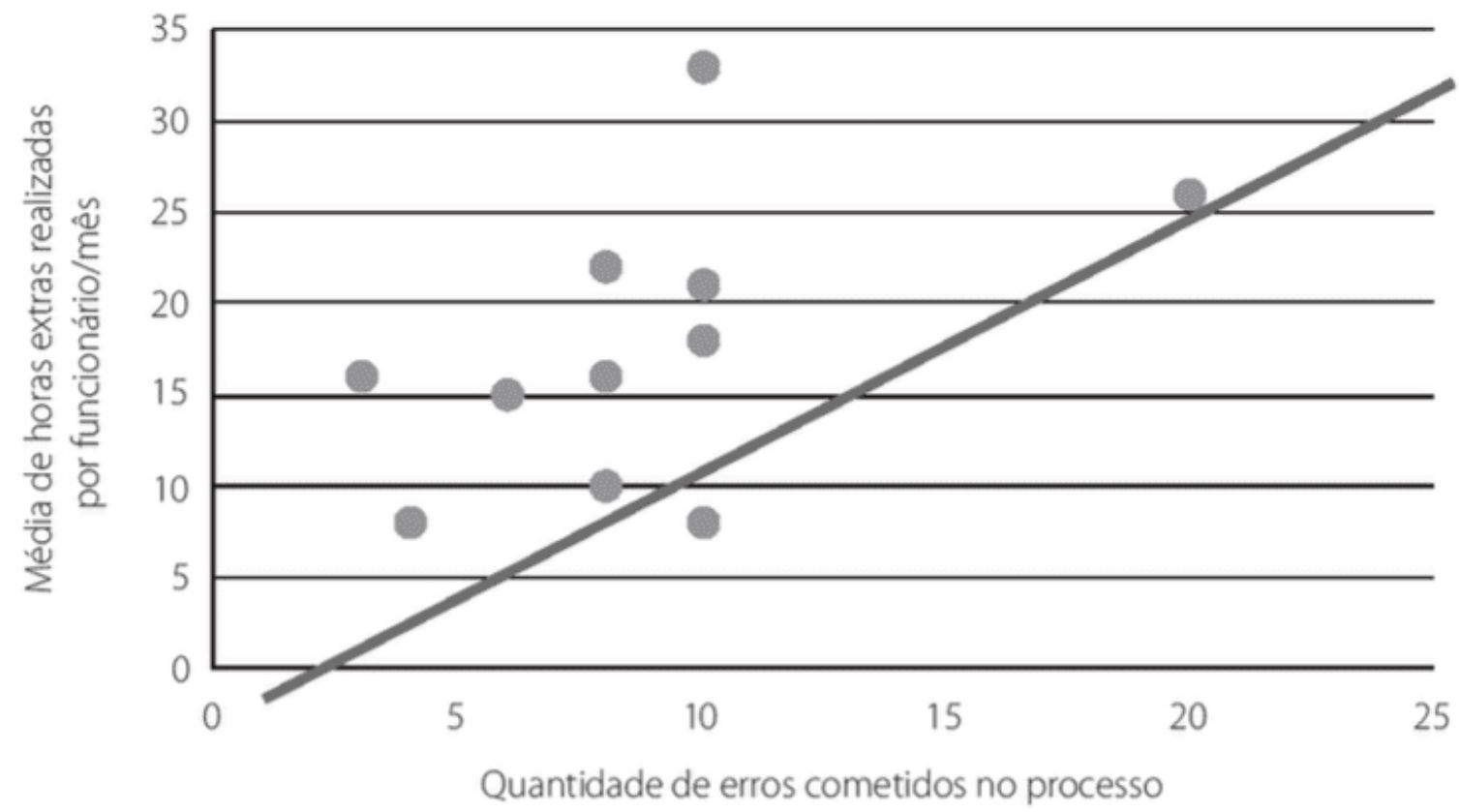

Fonte: Ferramentas da Qualidade, Barros (2014) - ADAPTAÇÃO

Fluxograma: "é a representação de um processo geralmente feita por meio de caixas de vários formados e de flechas que mostram a transição entre os elementos que o compõem". (MARTINELLI, 2014, p.116).

Segundo Mello (2011), o fluxograma serve para descrever os processos, sendo os seus símbolos todos padronizados, para as pessoas que os conheça, conseguir compreender com facilidade o funcionamento do processo, por causa disso e útil no controle da qualidade na empresa. 
Figura 9 - Exemplo de Fluxograma

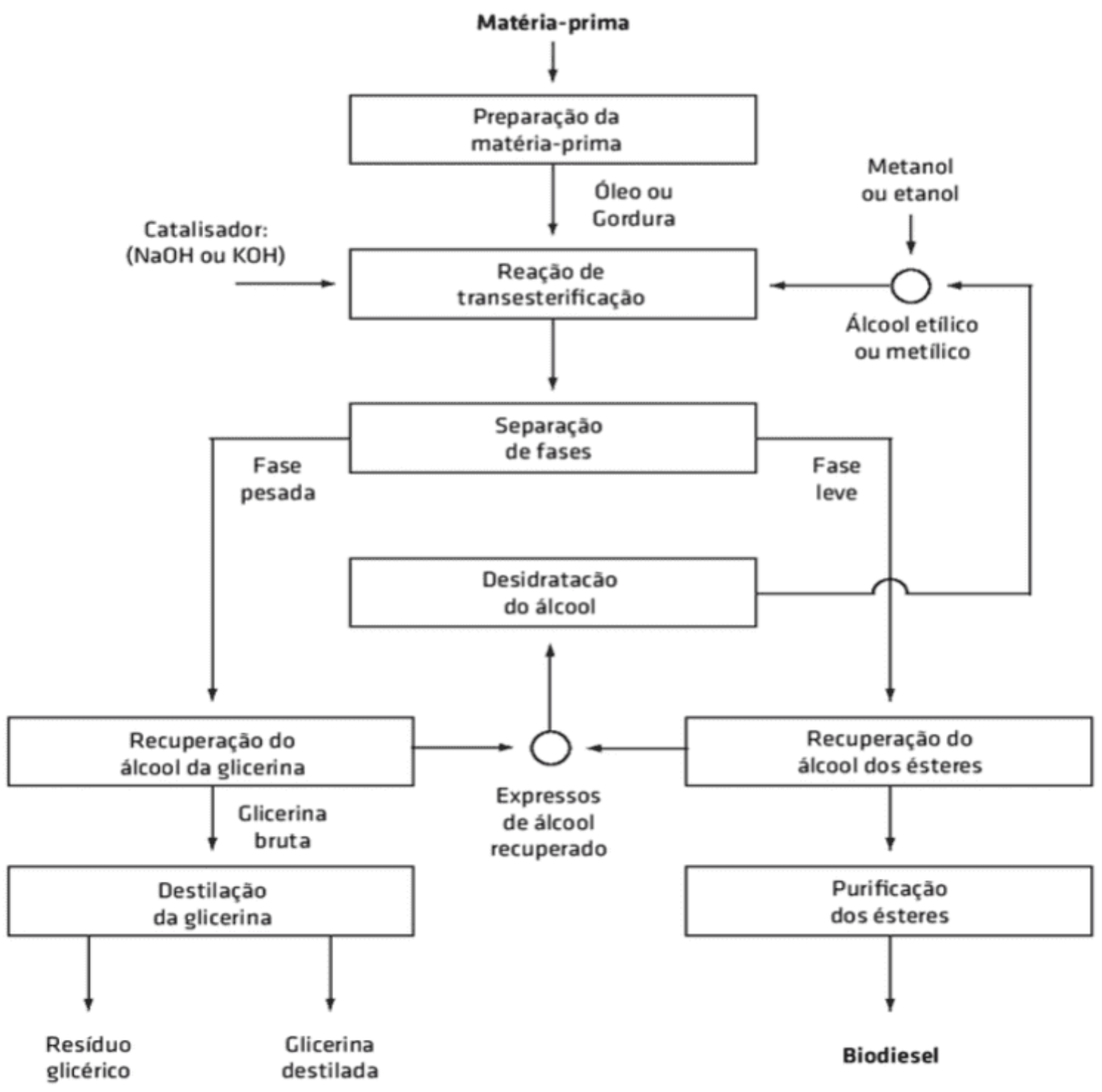

Fonte: Mapas, gráficos e redes, Martinelli (2014) - ADAPTAÇÃO

Gráfico de controle: "e um método que permite a análise da variação a qual um processo está submetido, e demostra se essa variação está dentro do padrão médio esperado ou se apresenta um desvio que necessita ser investigado". (BARROS,2014, p.59). 
Segundo Mello (2011), por mais que um processo seja controlado sempre haverá alguma variação, em alguma medida ela vai ter alguma instabilidade, desse modo controlar esse tipo de variação e importante para garantir a qualidade dos produtos.

Figura 10 - Exemplo de Gráfico de Controle

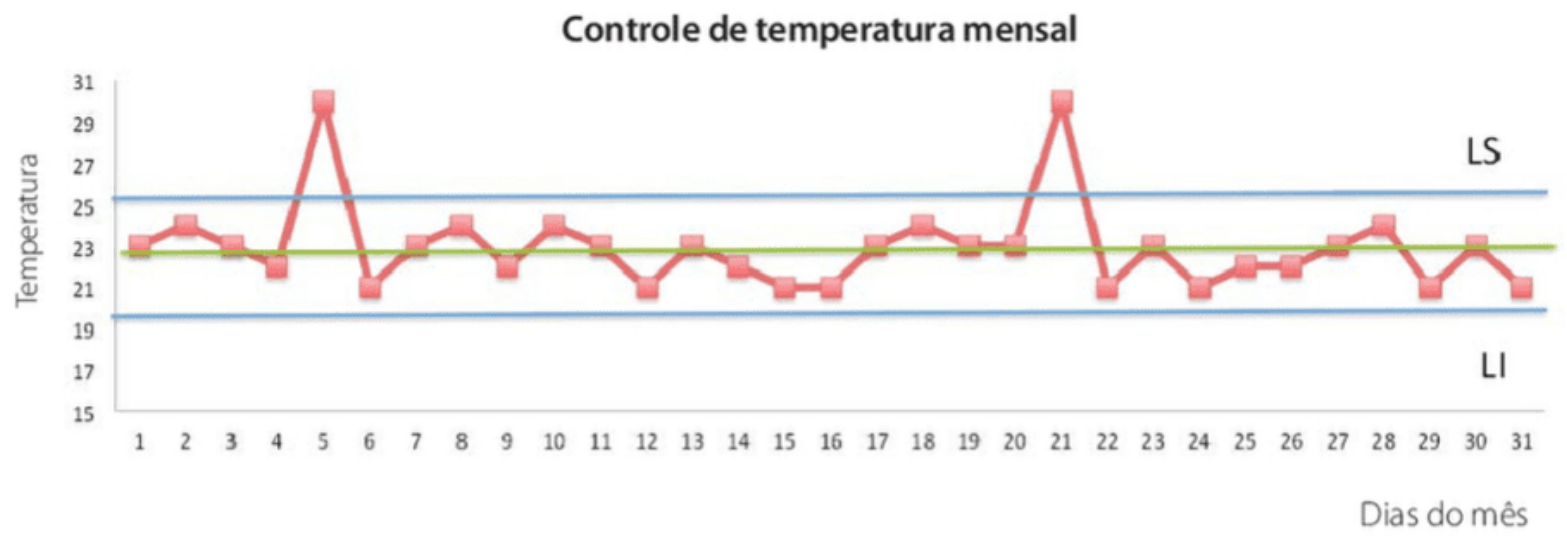

Fonte: Ferramentas da Qualidade, Barros (2014) - ADAPTAÇÃO

Para Bond (2012), e possível também utilizar no controle da qualidade o PDCA, 5W2H1R.

PDCA: ele e muito utilizado nas organizações para controle de processos tendo como objetivo a melhoria contínua. No primeiro estágio e necessário examinar o problema e coletar os dados para o desenvolvimento de um plano, No segundo estágio e preciso colocar em ação fazer o que for necessário, no terceiro estágio checar os resultados para averiguar se foram realizadas as melhorias, no ultimo estagio agir em consolidar as mudanças caso os resultados serem satisfatórios.(LAGE JUNIOR, 2016). 
Figura 11 - Ciclo PDCA

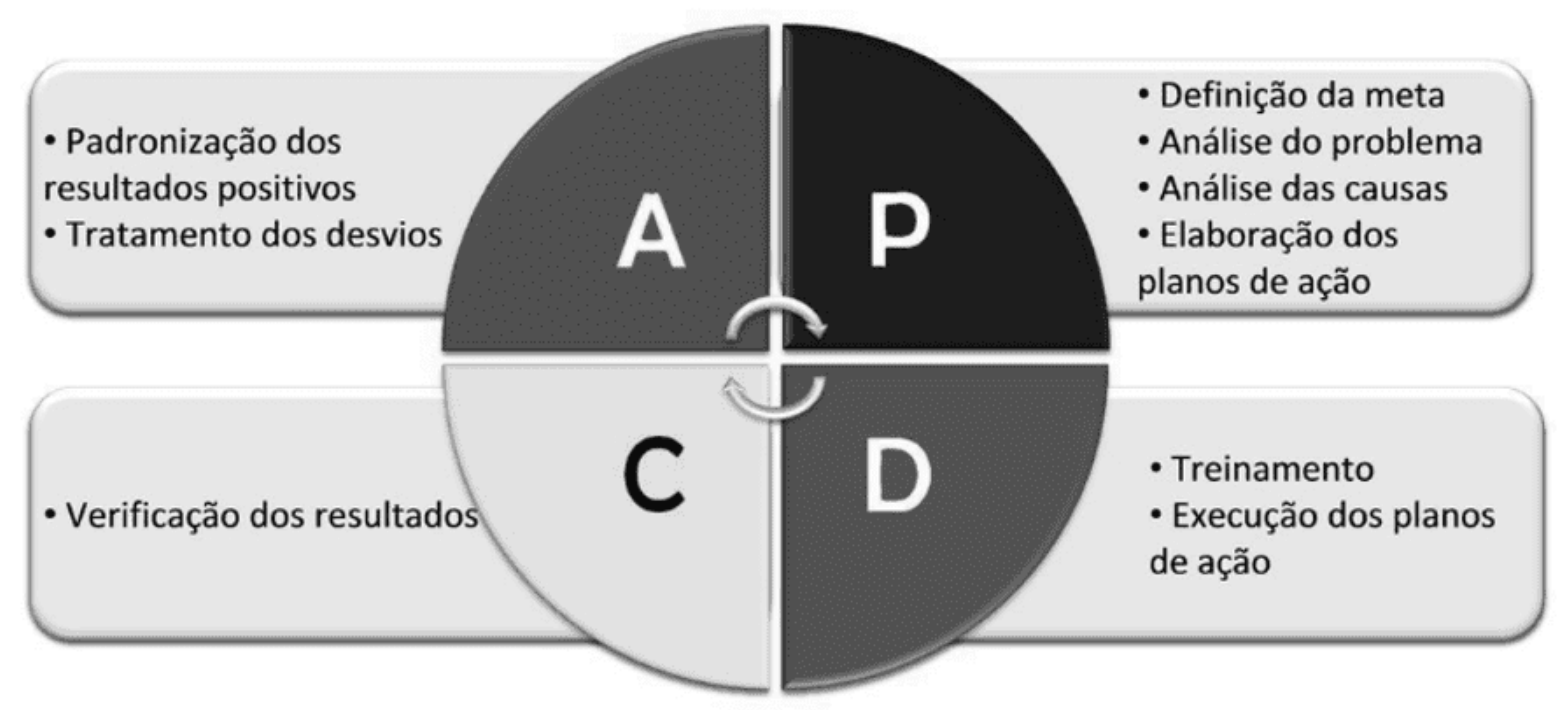

Fonte: Qualidade total: o que é e como alcançar, Bond (2012) - ADAPTAÇÃO

5W2H1R : " Trata-se de uma ferramenta utilizada para diagnóstico de problemas e planejamento de soluções e planos de ação".(LIU, 2015, p.131).

Tendo como objetivo definir as informações essências de um projeto ou plano de ação, tendo como vantagem a colocação na prática das responsabilidades de cada envolvido no grupo para a melhoria da qualidade; após a construção da tabela com as questões a serem discutidas e registradas as ações que serão necessárias. (BOND, 2012). 
Figura 12 - Detalhamento do 5W2H1R

\begin{tabular}{|l|l|}
\hline \multicolumn{1}{|c|}{ 5W2H1R } & \multicolumn{1}{c|}{ Detalhamento } \\
\hline Por quê? & Justificativa para execução da atividade ou o projeto. \\
\hline O quê? & O que será feito, as etapas. \\
\hline Quem? & Definição das responsabilidades para realização das atividades. \\
\hline Quando? & Cada uma das tarefas deverá ser executada dentro de qual prazo? \\
\hline Onde? & Local em que cada tarefa será realizada. \\
\hline Como? & O método que deverá ser utilizado para a realização de cada tarefa. \\
\hline Quanto? & O custo de cada etapa do projeto. \\
\hline Resultado & Deve ser descrito explicitamente o resultado esperado. \\
\hline
\end{tabular}

Fonte: Prevenção e tratamento de não conformidade, Liu (2015) - ADAPTAÇÃO

\section{CONSIDERAÇÕES FINAIS}

Com os estudos realizados no decorrer do desenvolvimento do trabalho, observar se que as organizações necessitam de uma gestão de qualidade nos produtos e serviços oferecidos, adotando políticas e ações de correções de processos, assim mantendo a melhoria constante, sobre um melhor controle da qualidade. Com a utilização das ferramentas da qualidade os gestores obtêm dados importantes para a solução dos possíveis problemas de conformidade assim formulando o plano de ação mais adequado, para a solução do processo de qualidade do produto oferecido aos seus clientes.

Deste modo e possível perceber a importância das ferramentas de qualidade na engenharia, sendo muito utilidade para análise dos dados, nos processos de fabricação de um produto ou serviço oferecido, que irá refletir no controle de qualidade, possibilitando satisfazer as expetativas dos possíveis compradores. Quando utilizadas mais de uma ferramenta ao mesmo tempo, o resultado final e mais preciso, dos possíveis problemas para serem solucionados com rapidez pelos funcionários responsáveis, garantindo assim a qualidade e atendimento das necessidades dos seus clientes. Assim tornando indispensável a sua utilização na gestão da qualidade, mais e preciso fazer uma análise estratégica para observar quais 
as mudanças necessárias na gestão que irá ocorrer, para uma melhora real nos processos de gestão.

\section{REFERÊNCIAS}

BARROS, Elsimar. BONAFINI, Fernanda. Ferramentas da Qualidade —São Paulo: Pearson Prentice Hall,2014. p. 39,40,89.

BONAFINI, Fernanda Cesar. Estatística —São Paulo: Pearson Prentice Hall,2015. p. 20.

BOND, Maria Thereza. Qualidade total: o que é e como alcançar / Maria thereza Bond, Angela Busse, Renato Pustilnick. - Curitiba: InterSaberes, 2012. p. $54,55,56,57,80,81$.

CARAVANTES, Geraldo R. PANNO, Cláudia C. KLOECKNER Mônica C. Administração teorias e processos 1ed. - São Paulo: Pearson Prentice Hall, 2005. p.175,176,180.

CHIAVENATO, Idalberto, Introdução á teoria geral da administração: uma revisão abrangente da moderna administração das organizações - 7.ed. rev e atual - Rio de Janeiro: Elsevier, 2003. p. 23, 186.

CUSTODIO, Marcos Franqui. Gestao da qualidade e produtividade/ Marcos Franqui Custodio. - São Paulo: Pearson Education do Brasil, 2015. p.103,104

GERHARDT, Tatiana Engel. SILVEIRA, Denise Tolfo. Coordenado pela Universidade Aberta do Brasil - UAB/UFRGS e pelo Curso de Graduação Tecnológica Planejamento e Gestão para o Desenvolvimento Rural da SEAD/UFRGS. - Porto Alegre: Editora da UFRGS, 2009. p.31,37.

GERMANO, Pedro Manuel Leal. GERMANO, Maria Izabel Simões. Sistema de Gestão: Qualidade e segurança dos alimentos/ Pedro Manuel Leal Germano, Maria Izabel Simões Germano[orgs.]. —São Paulo: Manole, 2013.p.24,25. 
LAGE JUNIOR, Muris. Mapeamento de processos de gestão empresarial / Muris Lage Junior - Curitiba: InterSaberes, 2016. p. 107.

LIU, Shih Lu. Prevenção e tratamento de não conformidade / Liu Shih Lu. —São Paulo: Pearson Prentice Hall,2015. p. 131,132.

MARTINELLI, Marcelo. Mapas, gráficos e redes: elabore você mesmo/Marcelo martinelli —São Paulo: Oficina de textos, 2014. p.116.

MAXIMIANO, Antônio C. Amaru. Introdução à Administração 7ed.rev.e ampl. -3 reimpr.0 - São Paulo: Atlas, 2009. p.4, 395.

MAXIMIANO, Antônio Cesar Amaru. Fundamentos de administração: manual compacto para as disciplinas TGA e introdução a administração. -2ed.-São Paulo: atlas, 2007. p. 8.

MELLO, Carlos Henrique Pereira. Gestao da qualidade / Carlos Henrique Pereira Mello. - São Paulo: Pearson Education do Brasil, 2011. P. 2,3,4,86,87,88,89.

SELEME, Robson. Controle da qualidade: as ferramentas essenciais / Robson Seleme, Humberto Stadler- Curitiba: InterSaberes, 2012. p. 11,18.

SILVA, Reinaldo O. da. Teoria da administração / Reinaldo O. da Silva. -São Paulo: Pearson Prentice Hall,2008. p. 324.

SILVA, Rosinda Angela da. Qualidade, padronização e certificação / Rosinda Angela da Silva. - Curitiba: InterSaberes, 2017. p. 25,26, 62,63,64.

Enviado: Fevereiro, 2020.

Aprovado: Novembro, 2020. 